\title{
Protection of chromium-nickel steel in hydrochloric acid solution by a substituted triazole
}

\author{
Ya. G. Avdeev, ${ }^{1 *}$ D. S. Kuznetsov, ${ }^{2}$ M. V. Tyurina, ${ }^{1}$ A. Yu. Luchkin, ${ }^{2}$ \\ and M. A. Chekulaev ${ }^{1}$
}

${ }^{1}$ K. E. Tsiolkovsky Kaluga state university, 248023 Kaluga, Russian Federation

${ }^{2}$ A. N. Frumkin Institute of Physical Chemistry and Electrochemistry, Russian Academy of Sciences, Leninskii pr. 31, Moscow, 119071 Russian Federation *E-mail: avdeevavdeev@mail.ru

\section{Abstract}

The corrosion of chromium-nickel steel $12 \mathrm{Kh} 18 \mathrm{~N} 10 \mathrm{~T}$ in $2.0 \mathrm{M} \mathrm{HCl}\left(t=20-100^{\circ} \mathrm{C}\right)$ was studied using mass loss, potentiometric, and polarization methods. Efficient steel protection under these conditions can be achieved by inhibitors such as triazole derivative IFKhAN-92, alone or in combination with hexamethylenetetramine in a molar component ratio of $1: 4$. The proposed mixed inhibitor often protects steel $12 \mathrm{Kh} 18 \mathrm{~N} 10 \mathrm{~T}$ in $\mathrm{HCl}$ solutions in a broad temperature range, $20-100^{\circ} \mathrm{C}$, more efficiently than IFKhAN-92 alone at the same concentrations. The triazole in question and its blend with urotropine ensure metal protection in acid solutions for at least $8 \mathrm{~h}$. Since for IFKhAN-92 alone and its blend with urotropine the corrosion inhibition coefficients grow with an increase in temperature, at least to $\mathrm{t}=100^{\circ} \mathrm{C}$, they should be attributed to so-called "high-temperature inhibitors of acid corrosion". The presence of inhibitors of interest in the solution considerably increases the fraction of diffusion control in the corrosion process, as indicated by the significant decrease in effective activation energy in the presence of these compounds. Steel corrosion occurs in the active dissolution region both in background and inhibited acid solutions. The corrosion potential of steel is more positive in solutions containing inhibitors because they predominantly slow down the anodic reaction. Addition of IFKhAN-92 or its mixture with urotropine to an $\mathrm{HCl}$ solution hinders considerably the electrode reactions on steel in the entire temperature range studied. In this case, the cathodic and anodic current densities decrease with time, while the inhibition coefficients of electrode reactions either increase or remain nearly constant. The corrosion potentials decrease with time in the presence of the additives in question at $t=20-60^{\circ} \mathrm{C}$, which suggests that hindrance of the cathodic reaction is predominantly improved due to adsorption of inhibitors. It has been shown that the efficient inhibition of stainless steel corrosion in $\mathrm{HCl}$ solution by addition of IFKhAN92 or IFKhAN-92 + urotropine results from strong hindrance of both electrode reaction on the metal by these inhibitors, which becomes stronger in time and remains in effect as the temperature increases.

Keywords: acid corrosion, corrosion inhibitors, stainless steel, triazoles. 


\section{Introduction}

Austenitic steels containing $18 \% \mathrm{Cr}$ and $8-10 \% \mathrm{Ni}$ are the most common corrosionresistant (stainless) steels. These steels are sufficiently resistant to many corrosive media and have high plasticity, heat resistance and weldability. These properties determine their wide application in technology for over 50 years. A significant drawback of these steels is that they have low resistance to $\mathrm{HCl}$ solutions, therefore, without additional protection means, nickel-chromium austenitic steels can only withstand contact with its dilute solutions at low temperatures [1].

The range of inhibitors recommended in recent years for protection of nickelchromium steels in hydrochloric acid mostly includes sulfur-containing compounds, such as substituted thioureas [2-4], thiazoles [5], thiophenes [6] and Captax [7]. Of these, only $\mathrm{N}$-methyl-N'-pyridin-2-ylthiourea [3], N-[(E)-1-(2-thienyl)methylidene]-N-(4-\{[(Z)-1-(2thienyl)-methylidene]amino\}phenyl)amine [6], and Captax [7] can provide a degree of metal protection exceeding 90\%. We have previously developed IFKhAN-92, an acid corrosion inhibitor that is a triazol derivative. It protects stainless steels $1 \mathrm{Kh} 18 \mathrm{~N} 9 \mathrm{~T}$ and $12 \mathrm{Kh} 18 \mathrm{~N} 10 \mathrm{~T}$ in $\mathrm{HCl}$ solutions not only from general corrosion but also from hydrogen absorption [8]. Its protective effect exceeds that of such a well-known corrosion inhibitor as catamin $\mathrm{AB}$.

It seems worthwhile to create a mixed inhibitor based on IFKhAN-92 that would protect nickel-chromium stainless steel $12 \mathrm{Kh} 18 \mathrm{~N} 10 \mathrm{~T}$ in $\mathrm{HCl}$ solutions in a broad temperature range (up to $100^{\circ} \mathrm{C}$ ). We have studied urotropine, which is widely used as a corrosion inhibitor in mineral acid solutions [9], as an additive to IFKhAN-92.

\section{Experimental procedure}

The corrosion rate of nickel-chromium steel 12Kh18N10T (composition, mass\%: $\mathrm{C}$ up to 0.12; $\mathrm{Si}$ up to 0.8 ; $\mathrm{Mn}$ up to 2 ; $\mathrm{Ni} 9-11 ; \mathrm{S}$ up to 0.02 ; $\mathrm{P}$ up to 0.035 ; $\mathrm{Cr} 17-19$; $\mathrm{Cu}$ up to 0.3; $\mathrm{Ti}$ up to $0.5 ; \mathrm{Fe}$ balance) in $\mathrm{HCl}$ solutions was determined from the mass loss of specimens (at least three samples per point) sized $25.0 \times 25.0 \times 1.0 \mathrm{~mm}, 50 \mathrm{ml}$ of acid solution per specimen, in the temperature range of $t=20-100^{\circ} \mathrm{C}$. Prior to a test, specimens were cleaned on abrasive discs with varying grain size (finest grit P600) and degreased with acetone.

Solutions were prepared from $\mathrm{HCl}$ of "chemically pure" grade and distilled water. The base concentration of IFKhAN-92 was $C_{\text {in }}=5.0 \mathrm{mM}$. Urotropine was studied as an additive enhancing the protective effect of IFKhAN-92. Due to the low solubility of IFKhAN-92, it was added to the acid solution as a solution in ethanol. The resulting ethanol concentration in the pickling solution did not exceed $1.2 \mathrm{~mol} / \mathrm{l}$.

The efficiency of inhibitors was estimated from the inhibition coefficient, $\gamma=k_{0} / k_{\text {in }}$, and the degree of protection $Z=\left[\left(k_{0}-k_{\text {in }}\right) / k_{0}\right] \cdot 100 \%$, where $k_{0}$ and $k_{\text {in }}$ are the corrosion rates in the non-inhibited solution and in the solution with the compound being studied, respectively. 
In order to quantitatively estimate the effect of the additive on the inhibitor, the mutual influence coefficients of the mixture components were calculated:

$$
K_{\mathrm{m}}=\frac{\gamma_{\operatorname{mix}}}{\prod_{i=1}^{m} \gamma_{i}}
$$

where $\gamma_{\text {mix }}$ is the corrosion inhibition coefficient for the inhibitor mixture and $\prod_{i=1}^{m} \gamma_{i}$ is the product of the corrosion inhibition coefficients for individual mixture components. If $K_{\mathrm{m}}<1$, the protection coefficient of the inhibitor components is mutually reduced; at $K_{\mathrm{m}}=1$, it shows an additive behavior; and only at $K_{\mathrm{m}}>1$ it should be concluded that the components of the inhibitor mixture mutually enhance protection.

Electrochemical measurements were carried out using a stationary electrode from $12 \mathrm{Kh} 18 \mathrm{~N} 10 \mathrm{~T}$ steel $(5.0 \times 5.0 \times 1.0 \mathrm{~mm})$ in a glass three-electrode thermally controlled cell (working solution volume $60 \mathrm{ml}$ ) with naturally aerated $2.0 \mathrm{M} \mathrm{HCl}$. The steel electrode potentials were measured against a silver chloride electrode and converted to the normal hydrogen scale. Prior to each experiment, a steel electrode was cleaned with emery paper (P600 grit) and degreased with acetone. During a potentiometric study, a steel electrode was placed in a solution to be studied and the electrode potential was recorded at certain time intervals with an EL-02.061 potentiostat until the potential reached a constant value, but for no less than $2 \mathrm{~h}$. To perform a voltammetric study, a potentiostat was used to record anodic and cathodic polarization curves at a dynamic potential scanning rate of $0.0005 \mathrm{~V} / \mathrm{s}$. The curves were recorded 1, 30, and $120 \mathrm{~min}$ after a steel electrode was placed in the working solution.

\section{Experimental results and discussion}

\section{Corrosion studies}

In $2.0 \mathrm{M} \mathrm{HCl}\left(60^{\circ} \mathrm{C}\right)$, addition of $5.0 \mathrm{mM}$ IFKhAN-92 slows down the corrosion of stainless steel $12 \mathrm{Kh} 18 \mathrm{~N} 10 \mathrm{~T} 27$-fold (Table 1). Corrosion is inhibited more strongly by IFKhAN-92 + urotropine mixtures, though urotropine alone $(5.0 \mathrm{mM})$ provides a $\gamma$ value 10.8 times smaller than 5.0 mM IFKhAN-92. Though the components of this mixture act antagonistically $\left(K_{\mathrm{m}}=0.44-0.49\right)$, its studies are important from practical point of view because they allow the consumption of the triazole used for metal protection to be decreased considerably. Of the combinations studied, the mixture of IFKhAN-92 and urotropine in molar ratio 1:4 has the highest efficiency and decreases the $k$ of steel 33-fold. In view of this, it seems expedient to perform a comparative study of the applicability of IFKhAN-92 alone or in combination with urotropine in molar ratio 1:4 for protection of steel $12 \mathrm{Kh} 18 \mathrm{~N} 10 \mathrm{~T}$ in $\mathrm{HCl}$ solutions in a broad temperature range. 
Table 1. Coefficients of steel $12 \mathrm{Kh} 18 \mathrm{~N} 10 \mathrm{~T}$ corrosion inhibition by the IFKhAN-92 + urotropine formulation at $C_{\mathrm{mix}}=5.0 \mathrm{mM}$ and the mutual effects of the inhibitor mixture components in $2.0 \mathrm{M} \mathrm{HCl}$ $\left(60^{\circ} \mathrm{C}\right)$. Test duration: $2 \mathrm{~h}$.

\begin{tabular}{cccccccc}
\hline $\boldsymbol{C}_{\text {IFKhAN-92 }}$ & $\mathbf{0 . 0}$ & $\mathbf{0 . 5}$ & $\mathbf{1 . 0}$ & $\mathbf{2 . 5}$ & $\mathbf{4 . 0}$ & $\mathbf{4 . 5}$ & $\mathbf{5 . 0}$ \\
\hline$C_{\text {urotropine }}$ & 5.0 & 4.5 & 4.0 & 2.5 & 1.0 & 0.5 & 0.0 \\
$\gamma$ & 2.5 & 32 & 33 & 32 & 31 & 30 & 27 \\
$K_{m}$ & - & 0.47 & 0.49 & 0.47 & 0.46 & 0.44 & - \\
\hline
\end{tabular}

The corrosion rate of steel $12 \mathrm{Kh} 18 \mathrm{~N} 10 \mathrm{~T}$ in $2.0 \mathrm{M} \mathrm{HCl}$ increases with $t$ (Table 2), whereas the value of $k$ increases 312 -fold upon temperature increase by $80^{\circ} \mathrm{C}$. Addition of $5.0 \mathrm{mM}$ IFKhAN-92 decreases the $k$ of steel 4.4- to 234-fold. An increase in temperature by $80^{\circ} \mathrm{C}$ in a solution inhibited with triazole accelerates corrosion only 5.9fold. At $t \leq 80^{\circ} \mathrm{C}$, the combination of $1.0 \mathrm{mM}$ IFKhAN-92 $+4.0 \mathrm{mM}$ urotropine provides 1.2-1.6 times higher $\gamma$ values than IFKhAN-92 itself at the same concentration. Only at $100^{\circ} \mathrm{C}$ is this combination somewhat less efficient than the individual triazole. It is generally believed that the maximum $\gamma$ coefficients of high-temperature inhibitors of acid corrosion of steel are found at temperatures above $80^{\circ} \mathrm{C}$ [10]. Since the temperature maximum of $\gamma$ was not reached in the temperature range studied, neither for individual IFKhAN-92 nor for its combination with urotropine, they can be attributed to hightemperature inhibitors.

Table 2. Corrosion rates $\left(k, \mathrm{~g} /\left(\mathrm{m}^{2} \cdot \mathrm{h}\right)\right)$, corrosion inhibition coefficients $(\gamma)$ and steady-state potentials* $\left(E_{\text {cor }}, \mathrm{V}\right)$ of steel $12 \mathrm{Kh} 18 \mathrm{~N} 10 \mathrm{~T}$ in $2.0 \mathrm{M} \mathrm{HCl}$ at various temperatures. Test duration: $2 \mathrm{~h}$.

\begin{tabular}{ccccccc}
\hline \multirow{2}{*}{ Inhibitor } & $\boldsymbol{k}, \boldsymbol{\gamma}$ & $\mathbf{5}$ Temperature, ${ }^{\circ} \mathbf{C}$ \\
\cline { 3 - 7 } & $k$ & 1.5 & 4.0 & 15.5 & 92.3 & 468 \\
\hline & $E_{\text {cor }}$ & -0.14 & -0.14 & -0.12 & -0.12 & -0.11 \\
\hline \multirow{2}{*}{5.0 mM IFKhAN-92 } & $k$ & 0.34 & 0.52 & 0.57 & 1.1 & 2.0 \\
& $\gamma$ & 4.4 & 7.7 & 27 & 84 & 234 \\
& $E_{\text {cor }}$ & -0.07 & -0.09 & -0.09 & -0.09 & -0.09 \\
\hline \multirow{2}{*}{ 1.0 mM IFKhAN-92 + } & $k$ & 0.21 & 0.33 & 0.47 & 0.83 & 2.1 \\
4.0 mM urotropine & $\gamma$ & 7.1 & 12 & 33 & 111 & 223 \\
& $E_{\text {cor }}$ & -0.08 & -0.08 & -0.08 & -0.09 & -0.09 \\
\hline
\end{tabular}

*Steady-state $E_{\text {cor }}$ values established after $2 \mathrm{~h}$ of electrode exposure to a solution. 
Analysis of the temperature dependence of steel corrosion rate in $\mathrm{HCl}$ using the Arrhenius equation allowed us to estimate the effective activation energies $\left(E_{\mathrm{a}}\right)$ of this process. The calculation was based on the analysis of the $\ln k-T^{-1}$ plot (Figure 1). In $2.0 \mathrm{M} \mathrm{HCl}$, the effective activation energy of the corrosion process, $E_{\mathrm{a}}$, amounts to $66 \pm 1 \mathrm{~kJ} / \mathrm{mol}$, which indicates that the reaction occurs in a mixed kinetics zone. The presence of $5.0 \mathrm{mM}$ IFKhAN-92 or $1.0 \mathrm{mM}$ IFKhAN-92 + $4.0 \mathrm{mM}$ urotropine considerably increases the fraction of the diffusion component of the process $\left(E_{\mathrm{a}}=23 \pm\right.$ $2 \mathrm{~kJ} / \mathrm{mol})$.

The corrosion rate of steel $12 \mathrm{Kh} 18 \mathrm{~N} 10 \mathrm{~T}$ in $2.0 \mathrm{M} \mathrm{HCl}\left(t=60^{\circ} \mathrm{C}\right)$ increases during the first $0.5 \mathrm{~h}$ and then systematically decreases with time, at least until $8 \mathrm{~h}$ (Table 3). In this case, the $k$ value found from 8 -hour tests is 2.5 times smaller than the maximum corrosion rate calculated from 0.5-hour corrosion tests. In the presence of 5.0 mM IFKhAN-92, like in background solution, the $k$ value increases somewhat during the first $0.5 \mathrm{~h}$ and then decreases systematically. The $k$ value from a 8-hour test is 5.0 times smaller than that calculated from a 0.5 -hour corrosion test. In the entire time range studied, the minimum observed decrease in $k$ in comparison with the reference solution was 22 -fold. In the presence of $1.0 \mathrm{mM}$ IFKhAN-92 $+4.0 \mathrm{mM}$ urotropine, $k$ decreases with time of the corrosion test. A 32-fold increase in the corrosion test duration decreases $k 4$.5-fold. In the presence of $1.0 \mathrm{mM}$ IFKhAN-92 $+4.0 \mathrm{mM}$ urotropine, the $k$ value in comparison with the background solution is lower at least 23 -fold.

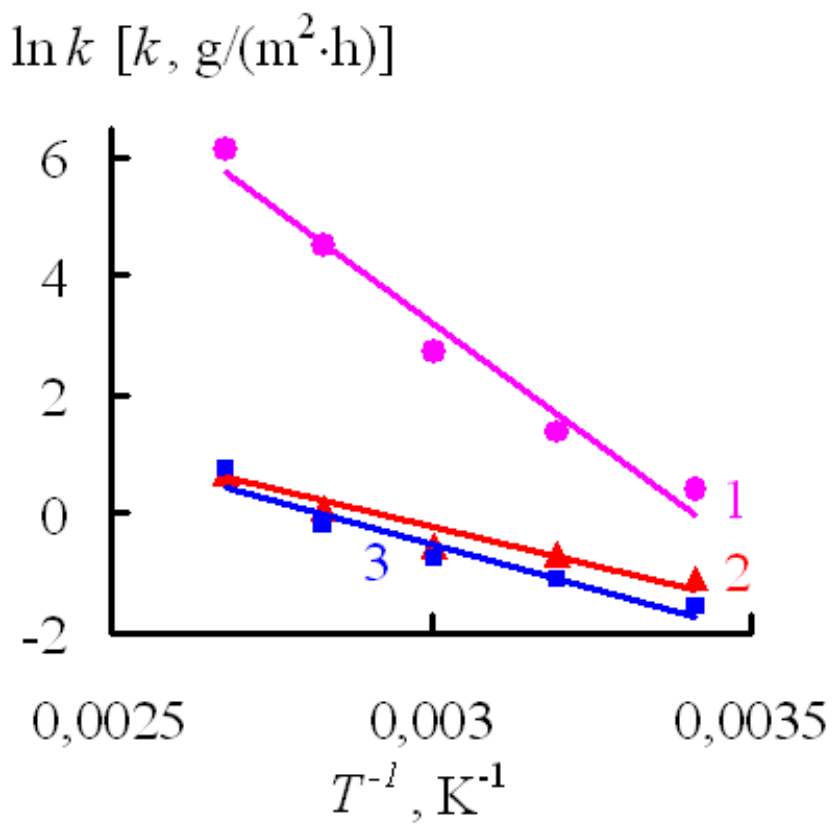

Figure 1. Dependence of $\ln k$ on $T^{-1}$ for corrosion of steel $12 \mathrm{Kh} 18 \mathrm{~N} 10 \mathrm{~T}$ in $2.0 \mathrm{M} \mathrm{HCl}(1)$ containing 5.0 mM IFKhAN-92 (2) or 1.0 mM IFKhAN-92 + $4.0 \mathrm{mM}$ urotropine (3). 
Table 3. Dependence of corrosion rate and coefficients of $12 \mathrm{Kh} 18 \mathrm{~N} 10 \mathrm{~T}$ steel corrosion inhibition in $2.0 \mathrm{M} \mathrm{HCl}\left(60^{\circ} \mathrm{C}\right)$ by IFKhAN-92 and its formulation on exposure time.

\begin{tabular}{cccccccc}
\hline \multirow{2}{*}{ Inhibitor } & $\boldsymbol{k}, \boldsymbol{\gamma}$ & \multicolumn{7}{c}{ Time, $\mathbf{h}$} \\
\cline { 5 - 8 } & & & $\mathbf{0 . 2 5}$ & $\mathbf{0 . 5}$ & $\mathbf{1}$ & $\mathbf{4}$ & $\mathbf{8}$ \\
\hline- & $k$ & 1.1 & 1.4 & 0.61 & 0.36 & 0.28 \\
\hline 5.0 mM IFKhAN-92 & $\gamma$ & 27 & 22 & 36 & 39 & 44 \\
\hline 1.0 mM IFKhAN-92+ & $k$ & 1.3 & 0.90 & 0.58 & 0.39 & 0.29 \\
4.0 mM urotropine & $\gamma$ & 23 & 34 & 37 & 38 & 42 \\
\hline
\end{tabular}

The $Z-C$ plot for IFKhAN-92 for the steel of interest in $\mathrm{HCl}$ solutions is $S$-shaped or similar (Figure $2 a$ ). A decrease in $C_{\text {IFKhAN-92 }}$ from $10 \mathrm{mM}$ to $0.01-0.1 \mathrm{mM}$ (depending on $t$ ) does not considerably decrease its $Z$. Probably, these parts of the curves correspond to the regions of maximum surface coverage by the inhibitor. At lower $C_{\text {IFKhAN-92 values, a }}$ decrease in the inhibitor content in solution results in a considerable loss of its protective action, up to corrosion stimulation. The higher is the solution temperature, the higher is the $C_{\text {IFKhAN-92 }}$ where it loses its protective action. In this case, the $Z$ values observed in the $C_{\text {IFKhAN-92 }}$ region corresponding to the maximum coverage of the metal surface by the inhibitor are higher where the temperature of the $\mathrm{HCl}$ solution is higher. The reason of the stimulating effect of low $C_{\text {IFKhAN-92 }}$ values on the corrosion of steels in mineral acid solutions was discussed in detail in our previous paper [11], namely, the inhibitor decreases the solution surface tension, thus facilitating the removal of hydrogen bubbles from the metal surface, while the electrode reactions are hindered by the inhibitor only slightly.

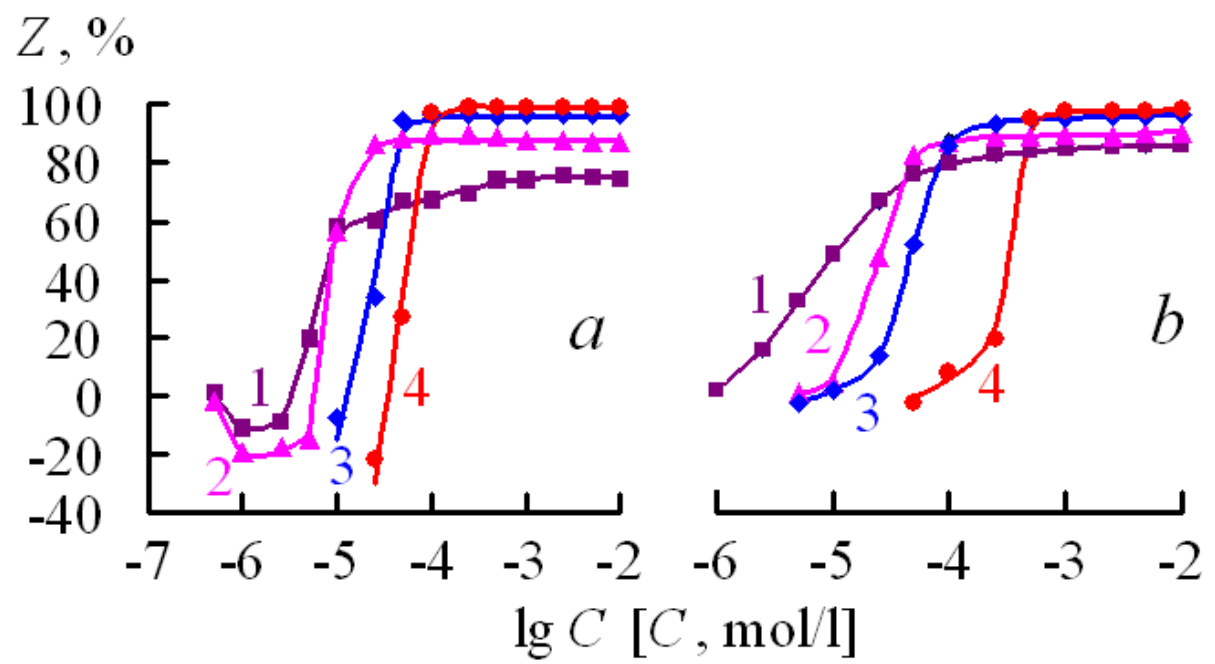

Figure 2. Dependence of the protective effect of IFKhAN-92 (a) and IFKhAN-92 + urotropine formulation $(1: 4)(b)$ on concentration for corrosion of 12Kh18N10T steel in $2.0 \mathrm{M} \mathrm{HCl}$ at various temperatures, ${ }^{\circ} \mathrm{C}: 20-1,40-2,60-3,80-4$. Test duration: $2 \mathrm{~h}$. 
The $Z-C$ plot for the IFKhAN-92 + urotropine mixture (mole ratio 1:4) has qualitatively the same character as that for IFKhAN-92 alone (Figure $2 b$ ). The difference is that a considerable loss of the protective effect by the mixture starts at its higher content in solution than in the case of IFKhAN-92. Other conditions being equal, the protective effect of the mixture is higher in the region corresponding to the maximum metal surface coverage by the inhibitor than that of IFKhAN-92. No corrosion stimulating effect of the mixed inhibitor was observed at its low concentrations.

Thus, a new combined inhibitor, IFKhAN-92 + urotropine (molar component ratio $1: 4$ ), has been developed that allows steel $12 \mathrm{Kh} 18 \mathrm{~N} 10 \mathrm{~T}$ to be protected in $\mathrm{HCl}$ solutions in a wide temperature range. The proposed blend ensures metal protection in an acid solution for at least $8 \mathrm{~h}$. It generally slows down the corrosion of stainless steel more efficiently than IFKhAN-92 itself.

\section{Electrochemical studies}

The corrosion potentials $\left(E_{\text {cor }}\right)$ of steel $12 \mathrm{Kh} 18 \mathrm{~N} 10 \mathrm{~T}$ in background $2.0 \mathrm{M} \mathrm{HCl}$ solution $\left(t=20-100^{\circ} \mathrm{C}\right.$ ) indicate that corrosion occurs in the active dissolution region (Figure 3 , Table 2). At $t=20^{\circ} \mathrm{C}, E_{\text {cor }}$ of steel decreases by $0.02 \mathrm{~V}$ in the first 3 minutes, does not change for some time, and then increases by $0.02 \mathrm{~V}$ in $45 \mathrm{~min}$ to a constant value that remains unchanged for more than $1 \mathrm{~h}$. The decrease in $E_{\text {cor }}$ observed during the first minutes can be explained by some hindrance of the cathodic reaction due to formation of hydrogen bubbles on the surface that shield the surface. The subsequent slower increase in $E_{\text {cor }}$ may be due to removal of hindrance of the cathodic process and/or inhibition of the anodic reaction. The character of $E_{\text {cor }}$ variation changes at higher temperatures. Immediately after the electrode is immersed in the solution, its $E_{\text {cor }}$ value starts to increase systematically $(7-110 \mathrm{~min})$ to a certain steady value. The higher the solution temperature, the more positive $E_{\text {cor }}$ value is established. The processes on the metal surface accelerate with an increase in temperature, which determines the trend towards a stronger and faster $E_{\text {cor }}$ ennoblement.

In $\mathrm{HCl}$ solutions inhibited with $5.0 \mathrm{mM}$ IFKhAN-92 or $1.0 \mathrm{mM}$ IFKhAN-92 $+4.0 \mathrm{mM}$ urotropine, like in background solutions, corrosion of $12 \mathrm{Kh} 18 \mathrm{~N} 10 \mathrm{~T}$ steel occurs in the region of steel active dissolution but with more positive $E_{\text {cor }}$ values. At $20^{\circ} \mathrm{C}$ at initial time instant, the $E_{\text {cor }}$ in the presence of the inhibitor or the inhibitor blend is higher by 0.10 and $0.09 \mathrm{~V}$, respectively, than that in the background solution, probably due to adsorption of the inhibitor on steel surface that predominantly hinders the anodic process. Inhibitor adsorption that occurs in the course of time, most likely, increases the hindrance of the cathodic process. As a result, a slow decrease in $E_{\text {cor }}$ is observed, followed by stabilization in the course of time. The $E_{\text {cor }}$ value in the presence of individual IFKhAN-92 is more positive than in the presence of its blend. At $t=40-80^{\circ} \mathrm{C}$, variation of $E_{\text {cor }}$ in solutions containing the additives in question shows a similar behavior, but the inhibitor blend increases $E_{\text {cor }}$ more strongly than IFKhAN-92 itself. At $t=100^{\circ} \mathrm{C}$, the $E_{\text {cor }}$ value is established at the initial instant of time and does not change for $2 \mathrm{~h}$. This value is most 
probably determined by adsorption of the inhibitors on the metal that occurs in time. As a result, anodic ionization of the metal occurs preferentially, thus $E_{\text {cor }}$ is more positive than that in the background. Under these conditions, equal $E_{\text {cor }}$ values are observed for $5.0 \mathrm{mM}$ IFKhAN-92 and its equimolar mixture with urotropine.

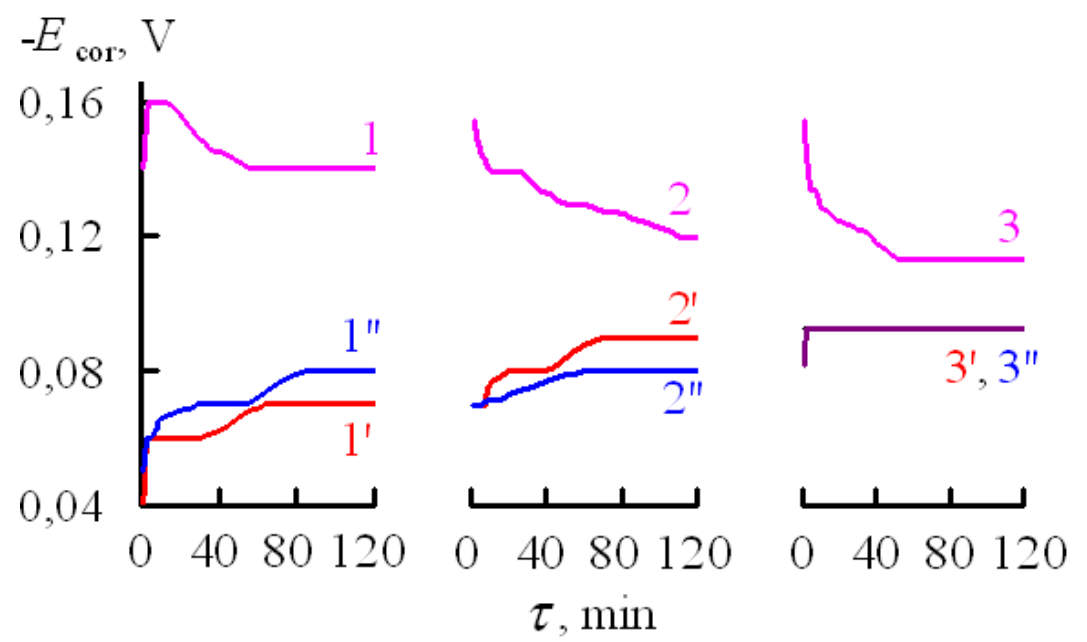

Figure 3. Dependence of corrosion potential of steel $12 \mathrm{Kh} 18 \mathrm{~N} 10 \mathrm{~T}$ in $2.0 \mathrm{M} \mathrm{HCl}$ on time at various temperatures, ${ }^{\circ} \mathrm{C}: 20-1,1^{\prime}, 1^{\prime \prime} ; 60-2,2^{\prime}, 2^{\prime \prime} ; 100-3,3^{\prime}, 3^{\prime \prime}$. Curves $1^{\prime}, 2^{\prime}, 3^{\prime \prime}-$ with addition of $5.0 \mathrm{mM}$ IFKhAN-92; $1^{\prime \prime}, 2^{\prime \prime}, 3^{\prime \prime}$ - with addition of $1.0 \mathrm{mM}$ IFKhAN-92 + $4.0 \mathrm{mM}$ urotropine.

Decreasing $C_{\text {in }}$ in $\mathrm{HCl}$ solution at $20^{\circ} \mathrm{C}$ decreases the efficiency of steel protection (Figure $4 a, b$ ). In parallel, $E_{\text {cor }}$ of steel decreases to become comparable to the value in the background solution at $C_{\text {in }} \leq 1 \cdot 10^{-5} \mathrm{M}$. In general, a correlation between $E_{\text {cor }}$ of steel in inhibited acid solution and the protective effect of the inhibitor is evident: the higher the $\gamma$ value of the inhibitor, the more positive the potential of steel. Nevertheless, the IFKhAN$92+$ urotropine blend, which is more efficient in steel corrosion inhibition, increases $E_{\text {cor }}$ of steel with respect to the background solution to a smaller extent than individual IFKhAN-92, other conditions being equal.

At $t=80^{\circ} \mathrm{C}$ in inhibited acid solutions, a more positive $E_{\text {cor }}$ value than in the background solution is maintained for IFKhAN-92 at $C_{\text {in }} \geq 1 \cdot 10^{-4} \mathrm{M}$, while this effect for the IFKhAN-92 + urotropine mixture is observed at $C_{\text {in }} \geq 5 \cdot 10^{-4} \mathrm{M}$ where a high protective effect of inhibitors is observed (Figure $4 c, d$ ). Decreasing the $C_{\text {in }}$ below these values abruptly decreases $\gamma$ and $E_{\text {cor }}$ of steel to values observed in the background solution. Like at $t=20^{\circ} \mathrm{C}$, a correlation is observed between the $E_{\text {cor }}$ of steel in the inhibited acid solution and $\gamma$, but it is less monotonous in this case.

More comprehensive information about the processes that occur on stainless steel surface in $\mathrm{HCl}$, both in the absence and in the presence of the inhibitors of interest, can be obtained by studying the regularities of the electrode reactions occurring in the system. 

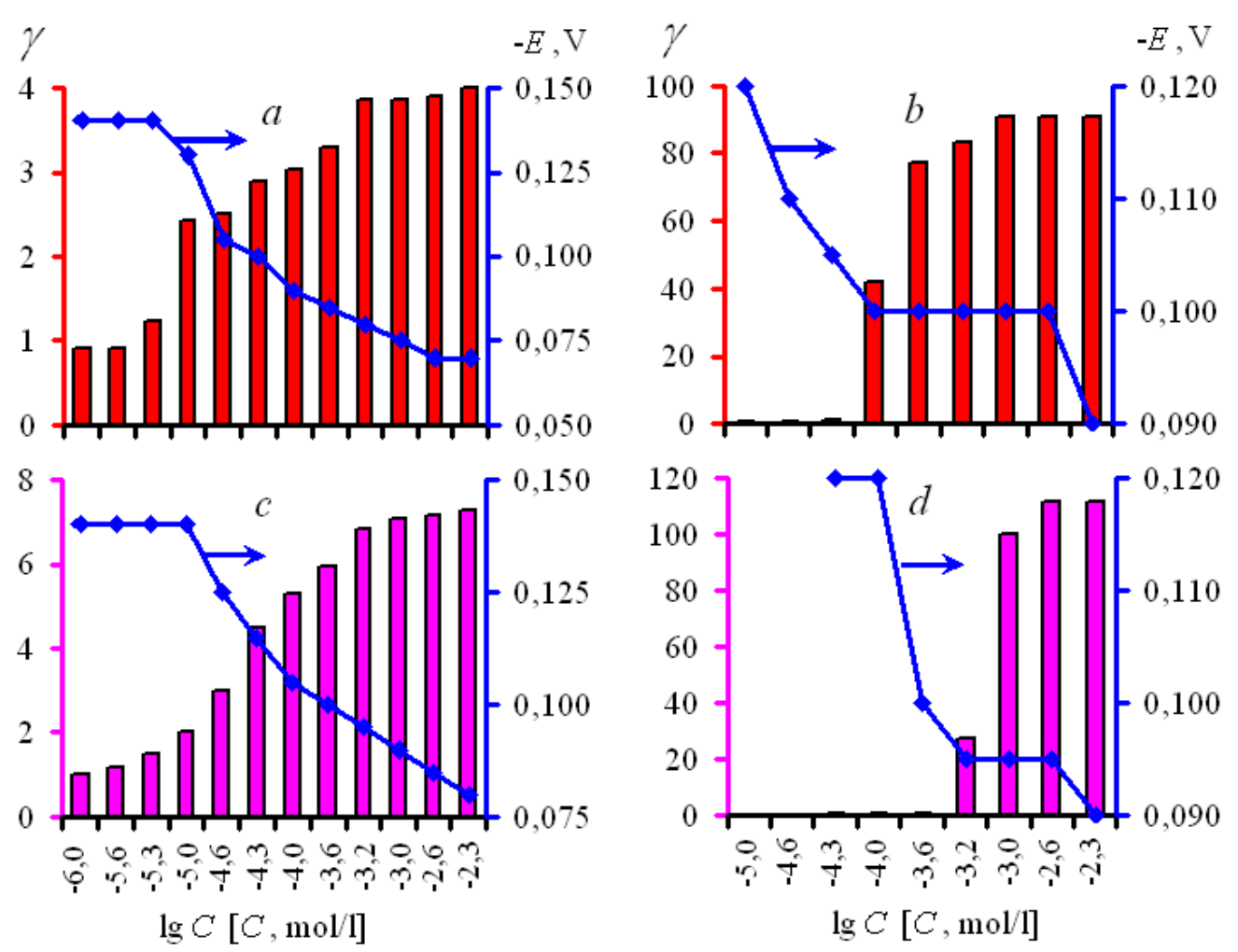

Figure 4. Corrosion potentials of $12 \mathrm{Kh} 18 \mathrm{~N} 10 \mathrm{~T}$ steel in $2.0 \mathrm{M} \mathrm{HCl}$ and corrosion inhibition coefficients by IFKhAN-92 $(a, b)$ or by the IFKhAN-92 + urotropine formulation $(1: 4)(c, d)$ at various inhibitor concentrations in the solution at various temperatures, ${ }^{\circ} \mathrm{C}: 20-a, c ; 80-$ $b, d$.

In $2.0 \mathrm{M} \mathrm{HCl}$ background solution $\left(t=20^{\circ}\right)$, the slopes of cathodic and anodic polarization of stainless steel (Figure 5, Table 4) are close to the values observed for individual alloy components, i.e., iron $(0.115$ and $0.065 \mathrm{~V})$ and nickel $(0.115$ and $0.070 \mathrm{~V})$ in acidic chloride-containing media [12]. An increase in the exposure time of steel electrode from $1 \mathrm{~min}$ to $0.5 \mathrm{~h}$ results in hindrance of both electrode reactions on the metal, mostly of the cathodic one, judging by $E_{\text {cor }}$ behavior. A longer exposure of a sample to the solution $(2 \mathrm{~h})$ does not affect considerably the anodic reaction but unhinders the cathodic reaction. Hindrance of anodic reaction is most likely to result from enrichment of the metal surface with nickel, i.e., the alloy component which is most resistant to dissolution. Some hindrance of the cathodic reaction observed in the initial period of time is a consequence of metal surface blocking by the appearing hydrogen bubbles. The subsequent removal of hindrance of the cathodic reaction is caused both by freeing of the metal surface from hydrogen bubbles and surface enrichment with nickel where the hydrogen evolution overvoltage is lower than on the other alloy components, i.e., $\mathrm{Cr}$ and Fe. It was noted previously [13] that at $E_{\text {cor }}$ of chromium steels in $\mathrm{H}_{2} \mathrm{SO}_{4}$, Ni has a lower dissolution rate than $\mathrm{Cr}$ or Fe and can be accumulated on steel surface. Since Ni has a lower hydrogen evolution overvoltage than chromium steel, accumulation of $\mathrm{Ni}$ on the surface shifts $E_{\text {cor }}$ in the positive direction, as shown for $25 \mathrm{Cr} 6 \mathrm{NiTi}$ steel corrosion in $\mathrm{H}_{2} \mathrm{SO}_{4}$. 


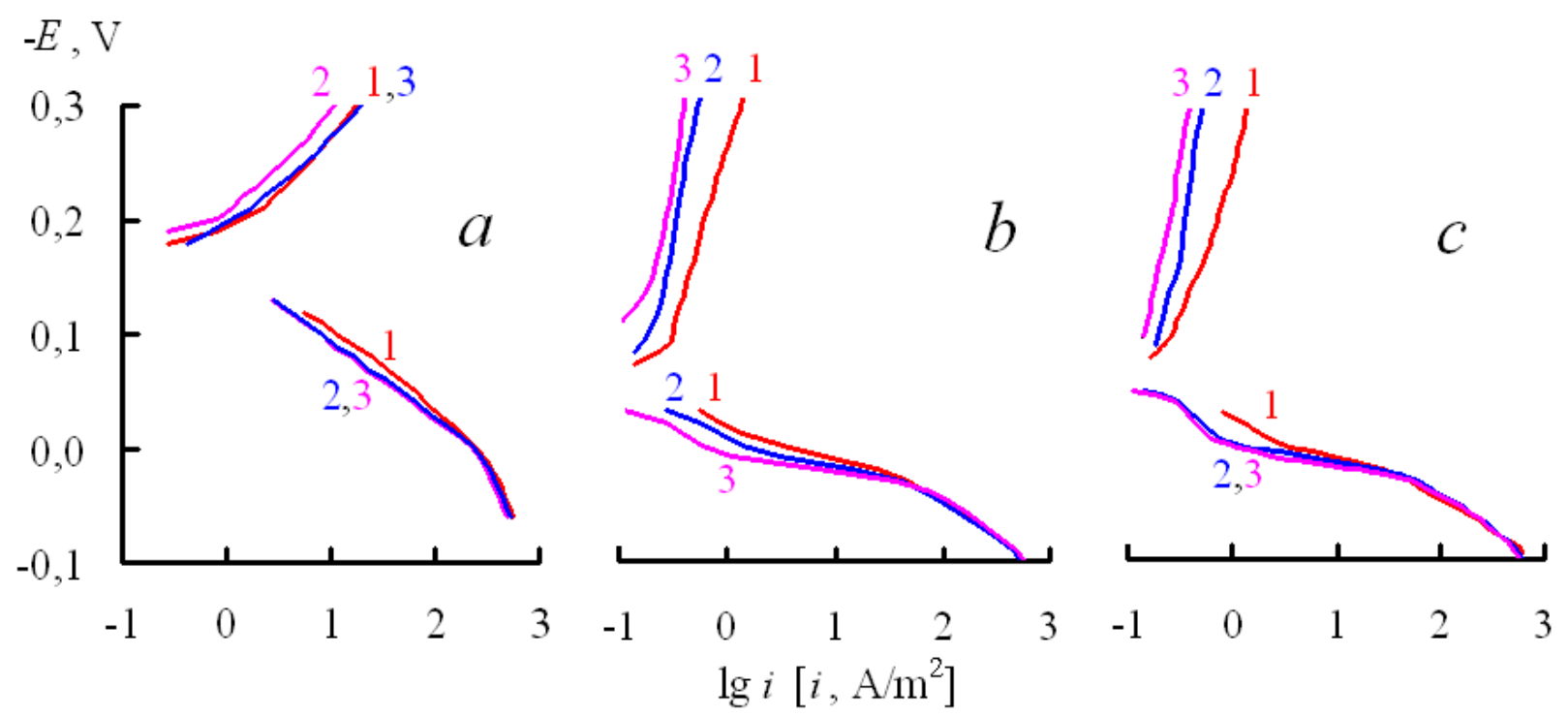

Figure 5. Polarization curves on steel $12 \mathrm{Kh} 18 \mathrm{~N} 10 \mathrm{~T}$ at $t=20^{\circ} \mathrm{C}$ in $2.0 \mathrm{M} \mathrm{HCl}(a)$ with

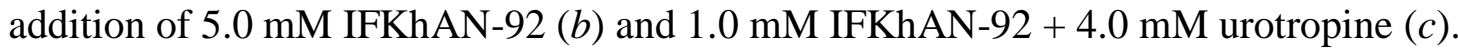
Preliminary electrode exposure to the solution, min: $1-1,30-2,120-3$.

The effect of enrichment of corroding steel surface with $\mathrm{Ni}$ is also observed in background solution at higher temperatures where the anodic process slows down somewhat with time of electrode exposure to the acid and the cathodic process accelerates (Figures 6,7 ). As a result, the $E_{\text {cor }}$ of steel increases with time.

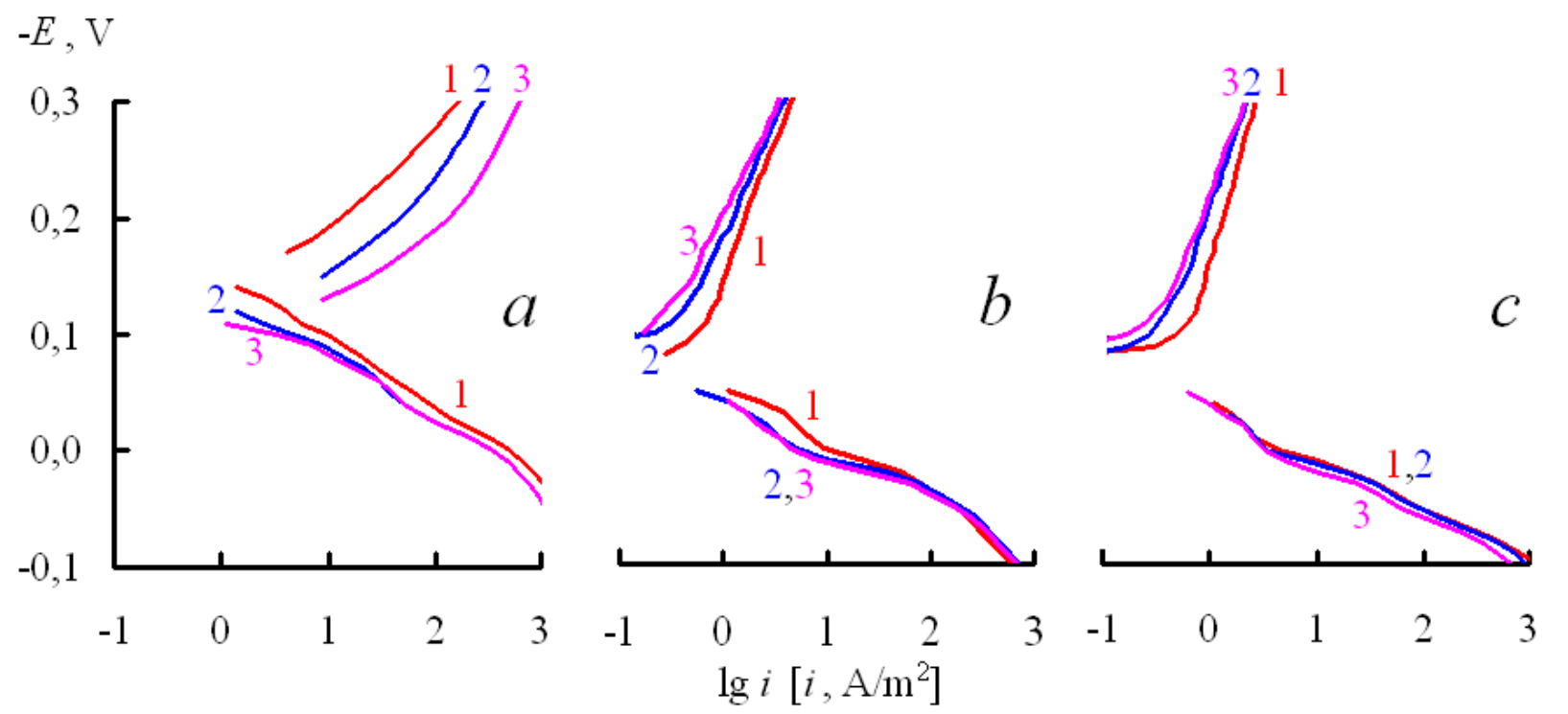

Figure 6. Polarization curves on steel $12 \mathrm{Kh} 18 \mathrm{~N} 10 \mathrm{~T}$ at $t=60^{\circ} \mathrm{C}$ in $2.0 \mathrm{M} \mathrm{HCl}(a)$ with addition of $5.0 \mathrm{mM}$ IFKhAN-92 $(b)$ and $1.0 \mathrm{mM}$ IFKhAN-92 + $4.0 \mathrm{mM}$ urotropine $(c)$. Preliminary electrode exposure to the solution, min: $1-1,30-2,120-3$. 
Table 4. Free corrosion potentials $\left(E_{\mathrm{cor}}\right)$, Tafel slopes $b_{\mathrm{c}}$ and $b_{\mathrm{a}}$, cathodic and anodic current densities $\left(i_{\mathrm{c}}\right.$ and $i_{\mathrm{a}}$ ), and inhibition coefficients for the cathodic and anodic reactions ( $\gamma_{\mathrm{c}}$ and $\left.\gamma_{\mathrm{a}}\right)$ of steel 12Kh18N10T in $2.0 \mathrm{M} \mathrm{HCl}$ as a function of electrode exposure time $(\tau)$ at $E=-0.25$ and $0.00 \mathrm{~V}$, respectively.

\begin{tabular}{|c|c|c|c|c|c|c|c|c|}
\hline Inhibitor & $\tau$, min & $E_{\text {cor }}, \mathbf{V}$ & $b_{c}, \mathbf{V}$ & $b_{\mathrm{a}}{ }^{*}, \mathrm{~V}$ & $i_{\mathrm{c}}, \mathrm{A} / \mathrm{m}^{2}$ & $i_{\mathrm{a}}, \mathbf{A} / \mathbf{m}^{2}$ & $\gamma_{c}$ & $\gamma_{\mathbf{a}}$ \\
\hline \multicolumn{9}{|c|}{$20^{\circ} \mathrm{C}$} \\
\hline \multirow{3}{*}{-} & 1 & -0.14 & 0.10 & 0.07 & 6.1 & 244 & - & - \\
\hline & 30 & -0.15 & 0.10 & 0.07 & 3.3 & 231 & - & - \\
\hline & 120 & -0.14 & 0.10 & 0.07 & 5.7 & 227 & - & - \\
\hline \multirow{3}{*}{$\begin{array}{c}5.0 \mathrm{mM} \text { IFKhAN- } \\
92\end{array}$} & 1 & -0.04 & $i_{\mathrm{d}}^{* *}$ & 0.07 & 0.92 & 3.3 & 6.6 & 73.9 \\
\hline & 30 & -0.06 & $i_{\mathrm{d}}$ & 0.07 & 0.42 & 1.4 & 7.9 & 165 \\
\hline & 120 & -0.07 & $i_{\mathrm{d}}$ & 0.07 & 0.35 & 0.58 & 16.3 & 391 \\
\hline \multirow{2}{*}{$\begin{array}{c}1.0 \mathrm{mM} \text { IFKhAN- } \\
92+\end{array}$} & 1 & -0.05 & $i_{\mathrm{d}}$ & 0.07 & 1.0 & 3.6 & 6.1 & 67.8 \\
\hline & 30 & -0.07 & $i_{\mathrm{d}}$ & 0.10 & 0.42 & 1.4 & 7.9 & 165 \\
\hline $4.0 \mathrm{mM}$ urotropine & 120 & -0.08 & $i_{\mathrm{d}}$ & 0.10 & 0.31 & 1.1 & 18.4 & 206 \\
\hline \multicolumn{9}{|c|}{$60^{\circ} \mathrm{C}$} \\
\hline \multirow{3}{*}{-} & 1 & -0.16 & 0.10 & 0.07 & 54.3 & 490 & - & - \\
\hline & 30 & -0.14 & 0.10 & 0.07 & 132 & 351 & - & - \\
\hline & 120 & -0.12 & 0.10 & 0.07 & 333 & 340 & - & - \\
\hline \multirow{3}{*}{$\begin{array}{c}5.0 \mathrm{mM} \text { IFKhAN- } \\
92\end{array}$} & 1 & -0.07 & $i_{\mathrm{d}}$ & 0.07 & 2.7 & 9.4 & 20.1 & 52.1 \\
\hline & 30 & -0.08 & $i_{\mathrm{d}}$ & 0.07 & 2.2 & 5.0 & 60.0 & 70.2 \\
\hline & 120 & -0.09 & $i_{\mathrm{d}}$ & 0.07 & 1.9 & 4.4 & 175 & 77.3 \\
\hline \multirow{2}{*}{$\begin{array}{c}1.0 \mathrm{mM} \text { IFKhAN- } \\
92+\end{array}$} & 1 & -0.07 & $i_{\mathrm{d}}$ & 0.07 & 1.9 & 4.4 & 28.6 & 111 \\
\hline & 30 & -0.08 & $i_{\mathrm{d}}$ & 0.07 & 1.4 & 3.3 & 94.3 & 106 \\
\hline $4.0 \mathrm{mM}$ urotropine & 120 & -0.08 & $i_{\mathrm{d}}$ & 0.07 & 1.3 & 3.3 & 256 & 103 \\
\hline \multicolumn{9}{|c|}{$100^{\circ} \mathrm{C}$} \\
\hline \multirow{3}{*}{-} & 1 & -0.15 & 0.10 & 0.08 & 63.3 & 1197 & - & - \\
\hline & 30 & -0.12 & 0.10 & 0.08 & 143 & 1170 & - & - \\
\hline & 120 & -0.11 & 0.10 & 0.08 & 3980 & 1011 & - & - \\
\hline \multirow{3}{*}{$\begin{array}{c}5.0 \mathrm{mM} \text { IFKhAN- } \\
92\end{array}$} & 1 & -0.08 & $i_{\mathrm{d}}$ & 0.08 & 11.7 & 47.2 & 5.4 & 25.4 \\
\hline & 30 & -0.09 & $i_{\mathrm{d}}$ & 0.08 & 7.8 & 13.3 & 18.3 & 88.0 \\
\hline & 120 & -0.09 & $i_{\mathrm{d}}$ & 0.08 & 4.2 & 8.3 & 948 & 122 \\
\hline \multirow{3}{*}{$\begin{array}{c}1.0 \mathrm{mM} \text { IFKhAN- } \\
92+ \\
4.0 \mathrm{mM} \text { urotropine }\end{array}$} & 1 & -0.09 & 0.10 & 0.08 & 35.5 & 54.7 & 1.8 & 21.9 \\
\hline & 30 & -0.09 & 0.10 & 0.08 & 24.2 & 50.8 & 5.9 & 23.0 \\
\hline & 120 & -0.09 & 0.10 & 0.08 & 2.2 & 48.3 & 1809 & 20.9 \\
\hline
\end{tabular}

$* b_{\mathrm{a}}$ values determined for the first linear section of anodic polarization curve.

$* * i_{\mathrm{d}}-$ limiting diffusion current. 


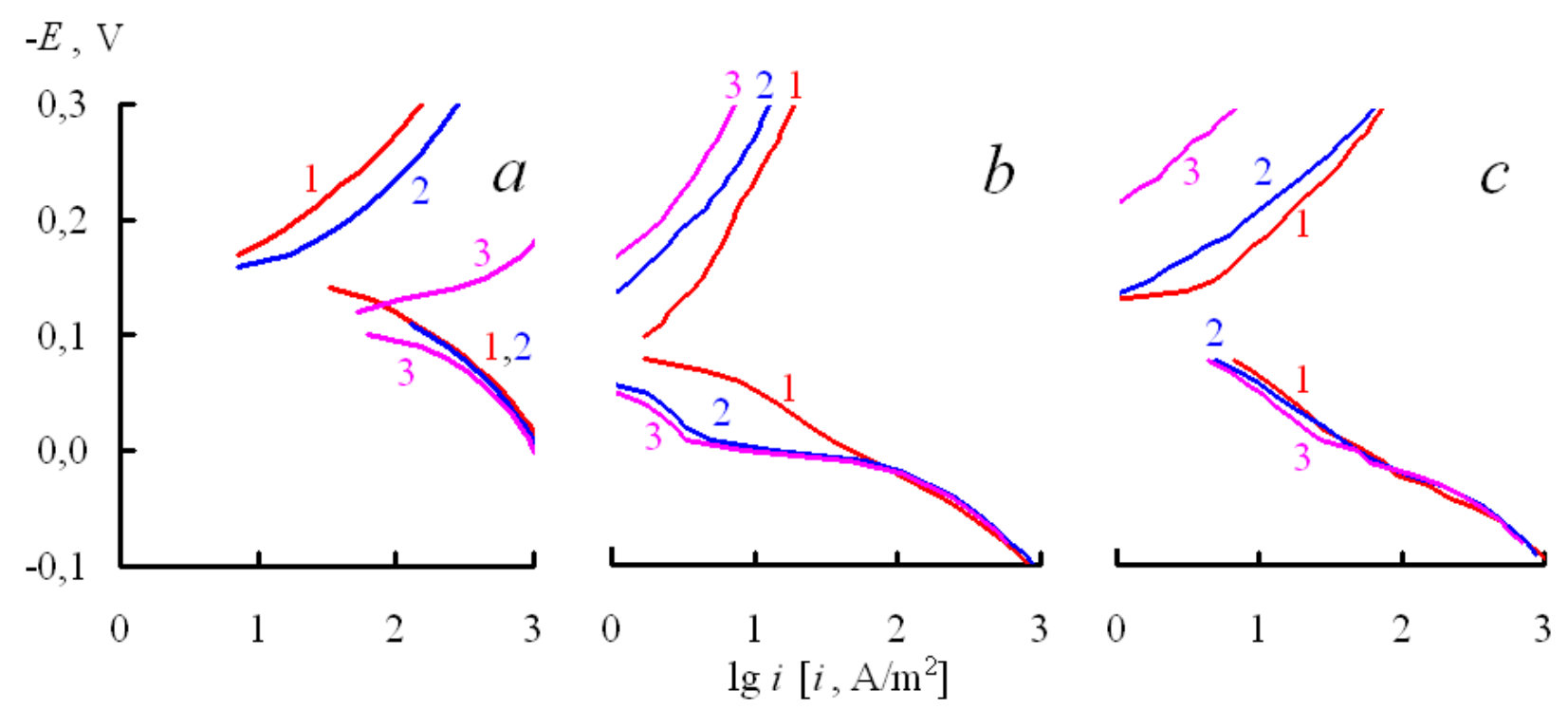

Figure 7. Polarization curves on steel $12 \mathrm{Kh} 18 \mathrm{~N} 10 \mathrm{~T}$ at $t=100^{\circ} \mathrm{C}$ in $2.0 \mathrm{M} \mathrm{HCl}(a)$ with addition of $5.0 \mathrm{mM}$ IFKhAN-92 $(b)$ and $1.0 \mathrm{mM}$ IFKhAN-92 + $4.0 \mathrm{mM}$ urotropine $(c)$. Preliminary electrode exposure to the solution, min: $1-1,30-2,120-3$.

Addition of IFKhAN-92 or its mixture with urotropine to an $\mathrm{HCl}$ solution hinders considerably the electrode reactions on steel in the entire temperature range. In this case, the cathodic and anodic current densities decrease with time, while the $\gamma$ values of electrode reactions either increase or remain nearly constant. The decrease in time of $E_{\text {cor }}$ at $t=20-60^{\circ} \mathrm{C}$ indicate that inhibition of the cathodic reaction due to adsorption of inhibitor additives occurs.

The cathodic polarization curves (PCs) in the presence of IFKhAN-92 or its formulation are characterized by a region of limiting diffusion current, which is typical of inhibitors that form polymolecular protective layers on the metal surface. It should be noted that the anodic PC of stainless steel in inhibited solutions of the acid has three linear parts. The nature and character of similar linear PC parts observed on $\mathrm{Fe}$ and $\mathrm{Ni}$ was discussed by us previously [14].

The efficient inhibition of stainless steel corrosion in $\mathrm{HCl}$ solution by addition of IFKhAN-92 or IFKhAN-92 + urotropine results from strong hindrance of both electrode reaction on the metal by these inhibitors, which becomes stronger in time and remains in effect as the temperature increases.

Thus, the surface of stainless steel $12 \mathrm{Kh} 18 \mathrm{~N} 10 \mathrm{~T}$ in background $\mathrm{HCl}$ solutions undergoes selective dissolution resulting in its enrichment with the nobler alloy component, i.e. $\mathrm{Ni}$, which preferentially hinders its anodic ionization but unhinders hydrogen reduction, hence $E_{\text {cor }}$ increases. In $\mathrm{HCl}$ solutions containing IFKhAN-92 or its formulation with urotropine, $E_{\text {cor }}$ of steel $12 \mathrm{Kh} 18 \mathrm{~N} 10 \mathrm{~T}$ is higher than in non-inhibited $\mathrm{HCl}$ solutions. This is a consequence of stronger hindrance of the anodic reaction due to inhibitor adsorption on the steel. Though adsorption of the inhibitor enhances the hindrance of the cathodic reaction with time, it is insufficient to decrease $E_{\text {cor }}$ to values 
observed in the background acid solution. It should be noted that enrichment of steel surface with $\mathrm{Ni}$ can also occur in inhibited $\mathrm{HCl}$ solutions, which should also enhance the inhibition of the anodic reaction. However, it is difficult to distinguish this effect against the efficient hindrance of the anodic reaction by the inhibitors being studied.

The IFKhAN-92 inhibitor developed by us and the mixtures on its basis show versatility in inhibition of steel corrosion in solutions of mineral acids. In acidic solutions, it slows down the dissolution of not only nickel-chromium steels but also low-carbon [1518] and high strength steels [19]. An important feature of this inhibitor is that it is applicable in a wide temperature range, both for protection of low-carbon steels $[16,17]$ and nickel-chromium steels.

\section{Conclusions}

1. A mixed inhibitor based on IFKhAN-92 (a triazole derivative) and urotropine (at a component ratio of $1: 4$ ) has been suggested. In many cases it provides better protection of steel $12 \mathrm{Kh} 18 \mathrm{~N} 10 \mathrm{~T}$ in $\mathrm{HCl}$ solution in a broad temperature range $\left(t=20-100^{\circ} \mathrm{C}\right)$ than IFKhAN-92 at the same concentrations.

2. At $t=20-100^{\circ} \mathrm{C}$, corrosion of steel $12 \mathrm{Kh} 18 \mathrm{~N} 10 \mathrm{~T}$ in $\mathrm{HCl}$ solution, both in the absence and in the presence of IFKhAN-92 or its formulation with urotropine, occurs in the region of mixed diffusion-kinetic control. It the inhibitors being studied are present in the solution, the fraction of diffusion control increases, as indicated by a significant decrease in the process activation energy in the presence of these compounds.

3. The corrosion of steel $12 \mathrm{Kh} 18 \mathrm{~N} 10 \mathrm{~T}$ in the $\mathrm{HCl}$ solutions studied, including those inhibited by IFKhAN-92 or its mixture with urotropine, occurs in the active dissolution region. In the presence of IFKhAN-92 or its formulation with urotropine, $E_{\text {cor }}$ increases in comparison with the values characteristic of the background solution. It is a consequence of inhibitor adsorption on steel surface resulting in preferential inhibition of metal anodic ionization.

\section{Acknowledgements}

This study was financially supported by the Russian Foundation for Basic Research and the Government of the Kaluga Region (Project no. 14-43-03037).

\section{References}

1. N. D. Tomashov and G. P. Chernova, Teoriya korrozii $i$ korrozionnostoyikie konstruktsionnyie splavyi (Theory of corrosion and corrosion-resistant structural alloys), Metallurgiya, Moscow, 1993, pp.173-194. (in Russian).

2. S. M. A. Hosseini and M. Salari, Ind. J. Chem. Technol., 2009, 16, November, 480.

3. Ramadev Herle, Prakash Shetty, S. Divakara Shetty and U. Achutha Kini, Int. J. Chem. Appl., 2011, 3, no. 2, 151.

4. R. Herle, P. Shetty, S. D. Shetty and U. A. Kini, Port. Electrochim. Acta, 2011, 29, no. 2,69 . 
5. A. S. Fouda and A. S. Ellithy, Corros. Sci., 2009, 51, 868.

6. M. Behpour, S. M. Ghoreishi, N. Soltani and M. Salavati-Niasari, Corros. Sci., 2009, 51, 1073.

7. B. P. Markhali, R. Naderi, M. Mahdavian, M. Sayebani and S. Y. Arman, Corros. Sci., 2013, 75, 269.

8. Ya. G. Avdeev, L. V. Frolova, Yu. I. Kuznetsov and O. O. Zel', Korroz.: mater., zasch., 2010, no. 8, 19 (in Russian).

9. A. I. Altsybeeva and S. Z. Levin, Ingibitory korrozii metallov (spravochnik) [Inhibitors of metal corrosion (Handbook)], Leningrad, Khimiya, 1968, 264 p. (in Russian).

10. E. S. Ivanov, Ingibitory korrozii metallov $v$ kislykh sredakh (Metal Corrosion Inhibitors in Acidic media), Metallurgiya, Moscow, 1986, 175 p. (in Russian).

11. Ya. G. Avdeev, P. A. Belinskii, Yu. I. Kuznetsov and O. O. Zel', Korroz.: mater., zasch., 2008, no. 8, 16 (in Russian).

12. S. M. Reshetnikov, Ingibitory kislotnoi korrozii metallov (Metal Corrosion Inhibitors in Acids), Khimiya, Leningrad, 1986, pp. 9-10 (in Russian).

13. A. A. Ots, Korroziya i iznos poverhnosteyi nagreva kotlov (Corrosion and wear of boilers heating surfaces), Energoatomizdat, Moscow, 1987, p. 164 (in Russian).

14. N. I. Podobaev, Ya. G. Avdeev, Protection of Metals, 1999, 35, no. 5, 484.

15. Ya. G. Avdeev, I. G. Gorichev and A. Yu. Luchkin, Int. J. Corros. Scale Inhib., 2012, 1, no. 1, 26.

16. Ya. G. Avdeev and A. Yu. Luchkin, Int. J. Corros. Scale Inhib., 2013, 2, no. 1, 53.

17. Ya. G. Avdeev, P. A. Belinskii, Yu. I. Kuznetsov and O.O. Zel', Protection of Metals and Physical Chemistry of Surface, 2010, 46, no. 7, 782.

18. Ya. G. Avdeev, M. V. Tyurina and Yu. I. Kuznetsov, Int. J. Corros. Scale Inhib., 2014, 3, no. 4, 246.

19. Ya. G. Avdeev, L. V. Frolova, Yu. I. Kuznetsov and O.O. Zel', Korroz.: mater., zasch., 2010, no. 5, 22 (in Russian). 